Удк 615.322

\title{
КОМПОНЕНТНЫЙ СОСТАВ ЭФИРНОГО МАСЛА МЕЛИССЫ ЛЕКАРСТВЕННОЙ ОКРЕСТНОСТЕЙ КРАСНОЯРСКА ПО ДАННЫМ ХРОМАТО-МАСС-СПЕКТРОМЕТРИИ
}

\author{
() А.А. Ефремов, И.Д. Зыкова", А.Е. Горбачев \\ Сибирский феедеральный университет, пр. Свободный, 79, Красноярск, \\ 660041 (Россия), e-mail: Aefremov@sfu-kras.ru
}

Методом исчерпывающей гидропародистилляции выделено эфирное масло надземной части мелиссы лекарственной, произрастающей в окресностях Красноярска. С использованием хромато-масс-спектрометрии идентифицированы 47 компонентов с содержанием более $0,1 \%$ от цельного масла. Основными компонентами масла являются цитронеллол $(36,71 \%)$ и гераниол $(27,20 \%)$. Кроме того, в составе масла содержится 10 компонентов с содержанием более $1 \%$ от суммы всех компонентов масла: бензиловый спирт $(1,67 \%)$, линалоол $(1,75 \%)$, цитронеллаль $(1,44 \%)$, нераль $(3,33 \%)$, гераниаль $(4,39 \%)$, кариофиллен $(3,73 \%)$, кариофиллен оксид $(1,40 \%)$, дибутилфталат $(1,36 \%)$, бутилизобутиловый эфир фталиевой кислоты $(2,45 \%)$ и фитол $(2,55 \%)$. Приведено сравнение компонентного состава масла мелиссы лекарственной различных регионов мира.

Ключевые слова: Melissa officinalis, эфирное масло, компонентный состав.

\section{Введение}

Сибирь - крупнейший регион России, располагающий огромным разнообразием лекарственных растений, которые уже давно используются в народной медицине. Известно более 500 лекарственных видов различных растений, которые произрастают в наших лесах, степях, на лугах.

Целебные свойства лекарственных растений объясняются тем, что в их листьях, стеблях, цветках или плодах содержатся витамины, вяжущие, пахучие и другие вещества, обладающие лечебным и профилактическим действием.

Мелисса лекарственная (Melissa officinalis L.) имеет 2000-летнюю историю применения в народной и научной медицине и является фармакопейным растением во многих странах мира, в том числе в Российской Федерации, внесена в Государственный реестр лекарственных средств [1, 2]. В Каноне врачебной науки более 1000 лет назад Авиценна указывал на лечебные свойства этого растения, называя мелиссу «усладой для сердца». Высоко ценил мелиссу и основатель врачебной химии (ятрохимии) Парацельс, который считал данное растение самым «золотым лекарством» из всех имеющихся средств [3].

Мелисса лекарственная - многолетнее эфиромасличное и пряное травянистое растение, вид рода Мелисса (Melissa) семейства Яснотковые (Lamiaceae), с сильноветвистым корневищем (рис.). В литературе встречаются также и другие названия растения, такие как лимонная трава, мята лимонная, маточник, кадило, пчельник. Родовое название растения Melissa переводиться с древнегреческого как «медоносная пчела», что указывает на прямую связь мелиссы с пчеловодством [4].

Прародиной мелиссы называют восточный район Средиземноморья до Персии, области Черного

Ефремов Александр Алексеевич - профессор, доктор

химических наук, e-mail: aefremov@ sfu-kras.ru

Зыкова Ирина Дементьевна - доцент кафедры химии,

e-mail: izykova@sfu-kras.ru

Горбачев Александр - студент,

e-mail: aefremov@sfu-kras.ru моря и Передней Азии. В диком виде мелисса распространена в Средней и Южной Европе, на Балканах, в Иране, Северной Африке, Северной Америке, Индии, а также на Украине, Кавказе, в Средней Азии [5, 6]. Мелиссу культивировали в

\footnotetext{
"Автор, с которым следует вести переписку.
} 


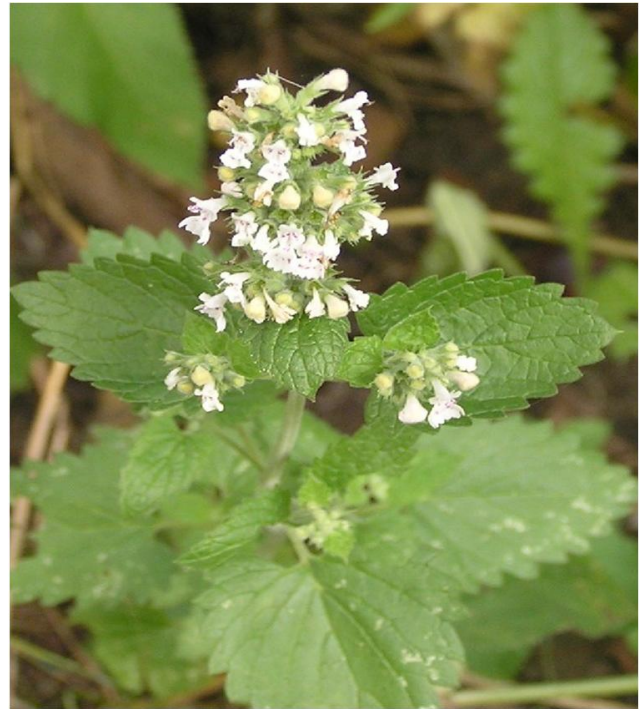

Мелисса лекарственная

(Melissa officinalis) в период цветения дореволюционной России и СССР. В настоящее время мелисса культивируется во многих странах, в том числе в России (Краснодарский край, Самарская область), в Литве, хорошо растет также в диком виде по опушкам лесов, лесным оврагам, ущельям, предпочитает глинистые и суглинистые почвы с достаточным увлажнением, хорошо освещенные и защищенные от холодных северных ветров. В некоторых странах ее ареал достигает высоты 1000 м над уровнем моря. Растение цветет в Сибири в июне-августе, плоды созревают в августе-сентябре.

Учитывая тот факт, что компонентный состав эфирного масла мелиссы лекарственной сибирского региона не описан в литературе, было важно исследовать его и сравнить содержание отдельных терпеноидов для различных районов ее произрастания.

\section{Методика эксперимента}

Исследуемое в данной работе растительное сырье надземную часть мелиссы лекарственной - собирали в августе 2013 г. в окрестностях города Красноярска, во время цветения, когда отмечается наибольшее содержание эфирного масла. Траву срезали на расстоянии 8-10 см от земли. Сырье раскладывали тонким слоем и сушили до воздушно-сухого состояния в затененном месте [7].

Эфирное масло получали методом исчерпывающей гидропародистилляции [8] в течение 20 ч до полного выделения всех летучих компонентов из исходного сырья исходя из навески воздушно сухого сырья 1200-1500 г. Плотность и показатель преломления полученного масла определяли с использованием высокоточных приборов фирмы Mettler Toledo [8].

Компонентный состав эфирного масла выявляли с использованием газового хроматографа Agilent Technologies 7890 A с масс-спектрометром Agilent Technologies 5975 С в качестве детектора. Анализируемый продукт (эфирное масло) объемом 10 мкл растворяли в 500 мкл $н$-гексана, добавляли 100 мкл гексанового раствора смеси, содержащей равные весовые количества нормальных углеводородов от $\mathrm{C}_{8}$ до $\mathrm{C}_{24}$ суммарной концентрации $0,1 \%$ масс. Анализ вели на кварцевой капиллярной колонке HP-5ms длиной 30 м и внутренним диаметром 0,25 мм, неподвижной фазой служил 5\%-дифенил-95\%-диметилсилоксан, толщина пленки неподвижной фазы 0,25 мкм. Использовали следующий температурный режим хроматографирования: начальная температура колонки $50{ }^{\circ} \mathrm{C}(2$ мин $)-50-240{ }^{\circ} \mathrm{C}(4 \%$ мин $)-240-280{ }^{\circ} \mathrm{C}\left(20^{\circ}\right.$ мин $)-280{ }^{\circ} \mathrm{C}$ в течение 5 мин. Температура испарителя $280{ }^{\circ} \mathrm{C}$, температура ионизационной камеры $-170{ }^{\circ} \mathrm{C}$, энергия ионизации - 70 эВ [9].

Для идентификации отдельных компонентов определяли линейные индексы удерживания каждого компонента и сопоставляли их значения и полные масс-спектры с библиотечными данными [9-11]. При полном совпадении масс-спектров и линейных индексов удерживания идентификация считалась окончательной. Количественный анализ проводили по площадям соответствующих пиков на хроматограмме, построенной по полному ионному току.

\section{Обсуждение результатов}

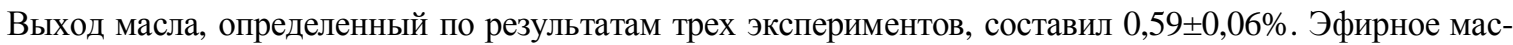
ло, собирающееся в верхней части насадки Клевенджера, представляет собой маслянистую жидкость бледно-

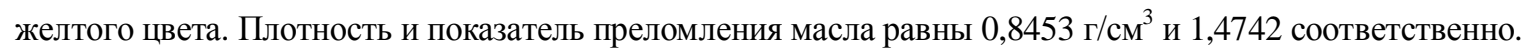

Методом хромато-масс-спектрометрии установлено, что в эфирном масле мелиссы лекарственной, произрастающей в окрестностях города Красноярска, содержится не менее 54 индивидуальных компонентов, 48 из которых имеют концентрацию более $0,1 \%$ от цельного масла, 47 из них идентифицированы в данной работе (табл. 1).

Как видно из представленных данных, мажорными компонентами полученного масла являются два спирта - цитронеллол и гераниол, содержание которых превышает $27 \%$ от цельного масла. Кроме того, 
в масле присутствуют также еще 10 компонентов с содержанием более $1 \%$, среди них максимальное количество составляют кариофиллен, нераль, фитол, бутил-изобутиловый эфир фталевой кислоты и гераниаль.

Ранее отмечалось, что район произрастания заметно сказывается на составе биологически активных соединений дикорастущих растений [12]. В связи с этим представляет интерес сравнить содержание основных компонентов эфирного масла мелиссы лекарственной, произрастающей в окрестностях города Красноярска и других регионах (табл. 2).

Таблица 1. Компонентный состав эфирного масла надземной части мелиссы лекарственной окрестностей Красноярска

\begin{tabular}{|c|c|c|c|}
\hline $\begin{array}{c}\text { Время удерживания, } \\
\text { мин }\end{array}$ & $\begin{array}{c}\text { Линейные индексы } \\
\text { удерживания }\end{array}$ & Компонент & $\begin{array}{c}\text { Содержание, \% от } \\
\text { цельного масла }\end{array}$ \\
\hline 7,38 & 971 & сабинен & 0,18 \\
\hline 9,10 & 1021 & мета-цимен & 0,44 \\
\hline 10,70 & 1032 & бензиловый спирт & 1,67 \\
\hline 11,03 & 1041 & фенилацетальдегид & 0,24 \\
\hline 12,05 & 1072 & транс-фуранолиналоолоксид & 0,25 \\
\hline 12,61 & 1088 & цис-фуранолиналоолоксид & 0,14 \\
\hline 13,03 & 1098 & линалоол & 1,78 \\
\hline 13,19 & 1102 & 2-ацетил-5-метилфуран & 0,13 \\
\hline 14,06 & 1125 & транс-розовый оксид & 0,13 \\
\hline 14,39 & 1137 & транс-пинокарвеол & 0,21 \\
\hline 14,61 & 1143 & нео-изопулегол & 0,15 \\
\hline 14,77 & 1147 & транс-фотоцитраль & 0,35 \\
\hline 14,91 & 1153 & цитронеллаль & 1,44 \\
\hline 15,65 & 1172 & 1-(3-метилфенил)этанон & 0,35 \\
\hline 15,95 & 1181 & изогераниаль & 0,22 \\
\hline 16,22 & 1190 & $\alpha$-терпинеол & 0,97 \\
\hline 16,79 & 1204 & транс-фотонерол & 0,47 \\
\hline 17,75 & 1232 & цитронеллол & 36,71 \\
\hline 18,05 & 1241 & нераль & 3,33 \\
\hline 18,68 & 1257 & гераниол & 27,20 \\
\hline 19,07 & 1271 & гераниаль & 4,39 \\
\hline 19,18 & 1274 & цитронеллил формиат & 0,12 \\
\hline 19,36 & 1282 & нерил формиат & 0,16 \\
\hline 19,71 & 1290 & мента-1,8-диен-2-ол ацетат & 0,12 \\
\hline 20,06 & 1302 & геранил формиат & 0,13 \\
\hline 20,42 & 1311 & винилгваякол & 0,14 \\
\hline 21,68 & 1350 & нафталин & 0,19 \\
\hline 21,90 & 1356 & гераниевая кислота & 0,44 \\
\hline 22,70 & 1384 & геранилацетат & 0,18 \\
\hline 22,85 & 1386 & $\beta$-бурбонен & 0,56 \\
\hline 23,85 & 1420 & кариофиллен & 3,73 \\
\hline 24,89 & 1451 & $\alpha$-химахален & 0,37 \\
\hline 24,97 & 1456 & $\beta$-(Е)-фарнезен & 0,28 \\
\hline 25,79 & 1481 & 1-этил-3,5-диизопропилбензол & 0,13 \\
\hline 25,88 & 1486 & В-(Е)-ионон & 0,13 \\
\hline 27,01 & 1526 & $\delta$-кадинен & 0,16 \\
\hline 28,61 & 1577 & мегастигматриенон & 0,12 \\
\hline 28,76 & 1585 & кариофиллен оксид & 1,40 \\
\hline 31,21 & 1670 & кариофилла-3,8(13)-диен-5- $\beta$-ол & 0,16 \\
\hline 31,47 & 1682 & Е-азарон & 0,20 \\
\hline 35,73 & 1845 & гексагидрофарнезилацетон & 0,20 \\
\hline 37,47 & 1918 & не идентифицирован & 0,79 \\
\hline 37,60 & 1921 & метилпальмитат & 0,76 \\
\hline 38,19 & 1947 & изис-11-гексадеценовая кислота & 0,72 \\
\hline 38,47 & 1958 & дибутилфталат & 1,36 \\
\hline 38,58 & 1962 & бутил-изобутиловый эфир фталиевой кислоты & 2,45 \\
\hline 41,85 & 2100 & 5-додецилдигидро-2(3Н)-фуранон. & 0,13 \\
\hline 42,08 & 2110 & Фитол & 2,55 \\
\hline \multicolumn{3}{|r|}{ ИТОГО } & 98,43 \\
\hline & & ИТОГО ИДЕНТИФИЦИРОВАНО & 97,64 \\
\hline
\end{tabular}


Таблица 2. Содержание основных компонентов эфирного масла мелиссы лекарственной, произрастающей на территориях разных стран

\begin{tabular}{l|c|c|c|c|c}
\hline \multirow{2}{*}{\multicolumn{1}{c|}{ Компонент }} & \multicolumn{5}{|c}{ Содержание, \% от цельного эфирного масла } \\
\cline { 2 - 6 } & Украина [13] & Таджикистан [14] & Турция [15] & Италия [16] & $\begin{array}{c}\text { Россия } \\
\text { (Данная работа) }\end{array}$ \\
\hline Нераль & 6,00 & 31,50 & 12,22 & - & 3,28 \\
Цитронеллол & - & - & 25,24 & 6,20 & 36,71 \\
Цитронеллаль & 4,03 & 2,80 & 5,86 & 39,60 & 1,48 \\
Гераниаль & 8,21 & 43,20 & 38,13 & - & 4,39 \\
Гераниол & - & 0,20 & 4,95 & 5,70 & 27,22 \\
Кариофиллен & 2,49 & 4,00 & - & 0,60 & 3,73 \\
Кариофиллен оксид & 10,26 & 0,40 & - & 0,20 & 1,40 \\
Линалоол & - & - & 2,74 & 0,70 & 1,78 \\
\hline
\end{tabular}

Из представленных данных видно, что содержание различных компонентов в эфирном масле мелиссы лекарственной, полученной в различных регионах, разное. Так, в масле Таджикистана и Турции основным компонентом является гераниаль, в то время как в масле Италии его нет. Вместо этого мажорным компонентом масла из Италии является цитронеллаль $(39,60 \%)$, в то время как в остальных маслах его содержание не превышает 6\%. В масле Украины и Таджикистана отсутствует цитронеллол, в то время как в масле Турции и Красноярска его содержание составляет 25 и почти $37 \%$ соответственно.

Отметим также, что в эфирном масле мелиссы лекарственной Ирана идентифицировано всего лишь 12 компонентов, а основным является транс-карвеол, содержание которого составило $28,9 \%$ от цельного масла [17].

Из данных, представленных в таблице 2, видно также, что среди основных компонентов эфирного масла мелиссы лекарственной наиболее полно представлено исследованное нами масло, так как в нем присутствуют все перечисленные в таблице основные компоненты.

\section{Заключение}

Таким образом, полученные результаты позволяют сделать вывод, что эфирное масло мелиссы лекарственной окрестностей Красноярска может представлять коммерческий интерес с точки зрения получения из него гераниола и цитронеллола, содержание которых в нем является доминирующим.

\section{Список литературь}

1. Koch-Heitzmann I., Schultze W. 2000 Jahre Melissa officinalis // Phytotherapie. 1988. Vol. 9. Pp. 77-85.

2. Государственный реестр лекарственных средств. М., 2008. 1208 с.

3. Куркин В.А. Основы фитотерапии. Самара, 2009. 963 с.

4. Мазнев Н.И. Энциклопедия лекарственных растений. М., 2004. 496 с.

5. Basar S., Zaman R. An Overview of Badranjboya (Melissa officinalis) // International Research Journal of Biological Sciences. 2013. Vol. 2. Pp. 107-109.

6. Moradkhani H., Sargsyan E., Bibak H., Naseri B., Sadat-Hosseini M., Fayazi-Barjin A., Meftahizade H. Melissa officinalis L., a valuable medicine plant: A review // Journal of Medicinal Plants Research. 2010. Vol. 4. Pp. $2753-$ 2759.

7. ГОСТ 24027.2-80. Сырьё лекарственное растительное. Методы определения влажности, содержания золы, экстрактивных и дубильных веществ, эфирного масла. М., 1980.12 с.

8. Ефремов А.А., Зыкова И.Д. Компонентный состав эфирных масел хвойных растений Сибири. Красноярск, 2013. $130 \mathrm{c}$.

9. Ткачев А. В. Исследование летучих веществ растений. Новосибирск, 2008. 969 с.

10. Adams R.P. Identification of Essential Oil Components by Gas Chromatography. Illinois, 2007. 804 p.

11. McLafferty F.W., Stauffer D.B. The Wiley / NBS registry of mass spectral data. London, 1989. 563 p.

12. Володарский Л.И. Практическое руководство по сбору и заготовке дикорастущих лекарственных растений. M., 1989. $112 \mathrm{c}$.

13. Гребенникова О. А., Палий А.Е., Логвиненко Л.А. Биологически активные вещества мелиссы лекарственной // Ученые записки Таврического национального университета им. В. И. Вернадского. 2013. Т. 26, №1. С. 43-50.

14. Sharopov F.S., Wink M., Khalifaev D.R., Zhang H., Dosoky N.S., Setzer W.N. Composition and Bioactivity of the Essential Oil of Melissa officinalis L. Growing Wild in Tajikistan // International Journal of Traditional and Natural Medicines. 2013. Vol. 2. Pp. 86-96.

15. Adinee J., Piri K., Karami O. Essential Oil Component in Flower of Lemon Balm (Melissa officinalis L.) // American Journal of Biochemistry and Biotechnology. 2008. Vol. 4. Pp. 277-278. 
16. Almeida F., Frei F., Mancini E., Martino L, Feo V. Phytotoxic Activities of Mediterranean Essential Oils // Molecules. 2010. Vol. 15. Pp. 4309-4323.

17. Adinee J., Piri K., Karami A. Essential Oil in Flower of Lemon Balm (Melissa officinalis L.) // American Journal of Biochemistry and Biotechnology. 2008. Vol. 4. Pp. 277-278.

Поступило в редакиию 17 июля 2014 г.

После переработки 15 сентября 2014 г.

\section{Efremov A.A., Zykova I.D. , Gorbachev A.E. ESSENTIAL OIL COMPOSITION FROM ABOVE-GROUND PART OF MELISSA OFFICINALIS L.IN THE VICINITY OF KRASNOYARSK BY GC/MS-METHOD}

Siberian Federal University, Svobodnyi ave., 79, Krasnoyarsk, 660041 (Russia), e-mail: Aefremov@sfu-kras.ru

The method of exhaustive water and steam distillation was used for isolation of essential oil above-ground part of Melissa officinalis L. in the vicinity of Krasnoyarsk. The chemical components of the essential oil of Melissa officinalis L. were analyzed by capillary GC and GC/MS and 47 substances were identified. The main components of essential oil - citronellol $(36,71 \%)$ and geraniol $(27,20 \%)$. Moreover, in the oil contains 10 components containing more than $1 \%$ of all oil components: benzyl alcohol $(1,67 \%)$, linalool $(1,75 \%)$, citronellal $(1,44 \%)$, neral $(3,33 \%)$, geranial $(4,39 \%)$, caryophyllene $(3,73 \%)$, caryophyllene oxide $(1,40 \%)$, dibutyl phthalate $(1,36 \%)$, iso-butyl phthalic acid ester $(2,45 \%)$ and phytol $(2,55 \%)$. Chemical components of essential oil of Melissa officinalis L. showed significant differences in climatic and ecological conditions.

Keywords: Melissa officinalis, essential oil, component composition.

\section{References}

1. Koch-Heitzmann I., Schultze W. Phytotherapie, 1988, vol. 9, pp. 77-85.

2. Gosudarstvennyi reestr lekarstvennykh sredstv. [The State Register of medicines]. Moscow, 2008, 1208 p. (in Russ.).

3. Kurkin V.A. Osnovy fitoterapii. [Basics of phytotherapy]. Samara, 2009, 963 p. (in Russ.).

4. Maznev N.I. Entsiklopediia lekarstvennykh rastenii. [Encyclopedia of Medicinal Plants]. Moscow, 2004, 496 p. (in Russ.).

5. Basar S., Zaman R. International Research Journal of Biological Sciences, 2013, vol. 2, pp. 107-109.

6. Moradkhani H., Sargsyan E., Bibak H., Naseri B., Sadat-Hosseini M., Fayazi-Barjin A., Meftahizade H. Journal of Medicinal Plants Research, 2010, vol. 4, pp. 2753-2759.

7. GOST 24027.2-80. Syr'e lekarstvennoe rastitel'noe. Metody opredeleniia vlazhnosti, soderzhaniia zoly, ekstraktivnykh i dubil'nykh veshchestv, efirnogo masla. [State Standard 24027.2-80. Raw medicinal plant. Methods for determination of moisture, ash, extractives and tannins, essential oil]. Moscow, 1980,12 p. (in Russ.).

8. Efremov A.A., Zykova I.D. Komponentnyi sostav efirnykh masel khvoinykh rastenii Sibiri. [Component composition of essential oils of conifers in Siberia]. Krasnoyarsk, 2013, 130 p. (in Russ.).

9. Tkachev A.V. Issledovanie letuchikh veshchestv rastenii. [The study of plant volatiles]. Novosibirsk, 2008, 969 p. (in Russ.).

10. Adams R.P. Identification of Essential Oil Components by Gas Chromatography. Illinois, 2007. 804 p.

11. McLafferty F.W., Stauffer D.B. The Wiley / NBS registry of mass spectral data. London, 1989. 563 p.

12. Volodarskii L.I. Prakticheskoe rukovodstvo po sboru i zagotovke dikorastushchikh lekarstvennykh rastenii. [Practical guidance on the collection and harvesting of wild medicinal plants]. Moscow, 1989, 112 p. (in Russ.).

13. Grebennikova O. A., Palii A.E., Logvinenko L.A. Uchenye zapiski Tavricheskogo natsional'nogo universiteta im. V.I. Vernadskogo, 2013, vol. 26, no. 1,pp. 43-50. (in Russ.).

14. Sharopov F.S., Wink M., Khalifaev D.R., Zhang H., Dosoky N.S., Setzer W.N. International Journal of Traditional and Natural Medicines, 2013, vol. 2, pp. 86-96.

15. Adinee J., Piri K., Karami O. American Journal of Biochemistry and Biotechnology, 2008, vol. 4, pp. 277-278.

16. Almeida F., Frei F., Mancini E., Martino L, Feo V. Molecules, 2010, vol. 15, pp. 4309-4323.

17. Adinee J., Piri K., Karami A. American Journal of Biochemistry and Biotechnology, 2008, vol. 4, pp. $277-278$.

Received July 17, 2014

\footnotetext{
* Corresponding author.
} 
